\title{
Removal of oxytetracycline from aqueous solutions by hydroxyapatite as a low-cost adsorbent
}

\author{
Maria Harja $^{1}$ and Gabriela Ciobanu ${ }^{1, *}$ \\ 1"Gheorghe Asachi" Technical University of Iasi, Faculty of Chemical Engineering and \\ Environmental Protection, Prof. dr. docent Dimitrie Mangeron Rd., no. 73, 700050, Iasi, Romania
}

\begin{abstract}
The present paper involved a study of the adsorption process of the oxytetracycline drug from aqueous medium by using the hydroxyapatite nanopowders as adsorbent materials. The batch adsorption experiments were performed by monitoring the solution $\mathrm{pH}$, contact time, adsorbent dosage and drug solution concentration. At $\mathrm{pH} 8$ and ambient temperature, high oxytetracycline removal rates of about $97.58 \%$ and $89.95 \%$ for the uncalcined and calcined nanohydroxyapatites, respectively, were obtained. The kinetic studies indicate that the oxytetracycline adsorption onto nanohydroxyapatite samples follows a pseudo-second order kinetic model. The maximum adsorption capacities of $291.32 \mathrm{mg} / \mathrm{g}$ and $278.27 \mathrm{mg} / \mathrm{g}$ for uncalcined and calcined nanohydroxyapatite samples, respectively, have been found. So, the conclusion can be drawn that the hydroxyapatite shows good adsorption ability towards oxytetracycline.
\end{abstract}

\section{Introduction}

In recent years, soil and water pollution by the antibiotic residues is a matter of growing preoccupation [1]. Among different groups of antibiotics, tetracyclines are of special concern because large quantities are applied in the therapy of human and animal infections and also at sub-therapeutic levels in animal feed as growth promoters. But, only a small amount of tetracyclines can be metabolized or absorbed by humans and animals. Residues of these antibiotics are accumulated in environmental waters and soil and they may lead to occurrence of resistant species [2]. The antibiotics occurrence in water environment exposes human beings and animals to constant low concentrations of antibiotics through drinking water contamination. A soil sorption study indicated that oxytetracycline, a major member of tetracyclines, is strongly adsorbed in soil regardless of soil type [3]. Broad scale monitoring studies have found oxytetracycline at concentrations as high as $300 \mu \mathrm{g} / \mathrm{kg}$ in some soils and up to $15 \mu \mathrm{g} / \mathrm{L}$ in some ground and surface waters [4]. The World Health Organization (WHO) recommends a guideline value of less than 1 ppb of antibiotic residues in the aquatic environment and less than $100 \mathrm{ppb}$ in soil respectively [5].

Therefore, efficient and inexpensive treatment methods for the removal of such compounds from the environment were developed. A low-cost strategy to remove

* Corresponding author: gciobanu03@yahoo.co.uk 
antibiotics from effluents at sewage treatment plants, after a traditional treatment, is to include a solid phase adsorption step. Adsorption of tetracyclines, oxytetracycline in the present case, on isolated clays, organic clays, soils, organic matters and marine sediment has been previously investigated [6-8].

Apatites are the most commonly occurring phosphate minerals on the Earth's crust, and consequently the primary natural sources of phosphorous in the biosphere [9]. Apatites are important in a great variety of natural and industrial processes. They are used as raw material in fertiliser production and in the remediation of contaminated soils [10]. Hydroxyapatite (HA), $\mathrm{Ca}_{10}\left(\mathrm{PO}_{4}\right)_{6}(\mathrm{OH})_{2}$, is similar to the biological apatite that is the main constituent of mammalian bone and teeth, and it is therefore a promising material for bone and tooth implants [11-13]. HA has been investigated as adsorbent for removing many toxic metal ions, dyes and other contaminants from aqueous solutions [14, 15].

The present work involved a study of the adsorption process of the oxytetracycline (OTC) from aqueous solutions by HA as adsorbent material. The reason for choosing $\mathrm{HA}$ as adsorbent is his non-toxicity, adsorption properties and low-cost material. Besides, the adsorption behaviour of OTC on HA has not yet been studied in the literature till now. Kinetic adsorption experiments were carried out to establish the effect of time on the adsorption process and to determine the adsorption rate for OTC removal.

\section{Experimental}

\subsection{Materials}

Calcium hydroxide $\mathrm{Ca}(\mathrm{OH})_{2}$, orthophosphoric acid $\mathrm{H}_{3} \mathrm{PO}_{4}$ (85 wt.\%), sodium hydroxide $\mathrm{NaOH}$, hydrochloric acid $\mathrm{HCl}$, ethanol $\mathrm{CH}_{3}-\mathrm{CH}_{2}-\mathrm{OH}$, and oxytetracycline hydrochloride $\mathrm{C}_{22} \mathrm{H}_{24} \mathrm{~N}_{2} \mathrm{O}_{9} \cdot \mathrm{HCl}$ were purchased from Sigma-Aldrich (Germany), all being of analytical grade and used without further purification.

\subsection{Preparation and characterization of nanohydroxyapatite adsorbents}

The uncalcined and calcined HA samples labeled $H A-u c$ and $H A-c$, respectively, were prepared by using $\mathrm{Ca}(\mathrm{OH})_{2}$ and $\mathrm{H}_{3} \mathrm{PO}_{4}$ as raw materials, as presented elsewhere [16, 17$]$. The HA powder was synthesised by the drop-wise addition of a $250 \mathrm{~mL}$ solution of $\mathrm{Ca}(\mathrm{OH})_{2}(0.1 \mathrm{M})$ to an appropriate amount of $\mathrm{H}_{3} \mathrm{PO}_{4}(0.1 \mathrm{M})$ aqueous solution to achieve predetermined $\mathrm{Ca} / \mathrm{P}$ atomic ratio of 1.67 , under magnetic stirring for $1 \mathrm{~h}$ at $60 \pm 1^{\circ} \mathrm{C}$. The pH was continuously monitored and adjusted to $11 \pm 0.5$ by adding $\mathrm{NaOH}(1 \mathrm{M})$ aqueous solution. The suspension was aged for $3 \mathrm{~h}$ at $60 \pm 1^{\circ} \mathrm{C}$ and then filtered and washed with ethanol and triply distilled water. The obtained powder was calcined at $800^{\circ} \mathrm{C}$ in an electrically heated furnace in order to increase its crystallinity.

The phase composition and average crystallite size of the as obtained HA powders were obtained by X-ray diffraction (XRD) with X'PERT PRO MRD diffractometer (PANalytical, Netherlands) using monochromatic $\mathrm{CuK} \alpha$ radiation $(\lambda=0.15418 \mathrm{~nm})$. The morphology and chemical composition of the samples were studied by scanning electron microscopy (SEM) coupled with energy dispersive X-ray spectroscopy (EDX) with QUANTA 200 3D microscope (FEI, Netherlands). The specific surface areas were evaluated by fitting the Brunauer-Emmett-Teller (BET) equation to the $\mathrm{N}_{2}$ adsorption isotherms recorded by a Quantachrome Nova 2200e Win2 apparatus. The $\mathrm{pH}$ at the point of zero charge $\left(\mathrm{pH}_{\mathrm{pzc}}\right)$ of the HA samples was determined by the $\mathrm{pH}$ drift method [18]. 


\subsection{Batch adsorption experiments}

All adsorption experiments were carried out using the batch equilibrium technique. Various OTC solutions with different initial concentrations are prepared by dilute of the OTC $(1000 \mathrm{mg} / \mathrm{L})$ stock solution. The influence of various parameters such as initial solution $\mathrm{pH}$, contact time, HA dose and OTC initial concentration on removal of OTC by HA samples ( $H A-u c$ and $H A-c)$ was investigated by varying one parameter at a time and keeping the remaining other parameters as constant. $\mathrm{HCl}$ and $\mathrm{NaOH}$ solutions were used to adjust the solution $\mathrm{pH}$. All pH measurements were realized with a Multi-Parameter Consort C831. The concentration of OTC in solutions was analysed by UV-Vis Jasco V-550 spectrophotometer at wavelength of maximum adsorption value of OTC ( $\left.\lambda_{\max }=355 \mathrm{~nm}\right)$. Each experiment was repeated three times and the given results were the average values.

The adsorption capacity $\left(q_{\mathrm{t}}, \mathrm{mg} / \mathrm{g}\right)$ at time $t$ and the removal rate $(R, \%)$ were determined using following equations:

$$
\begin{aligned}
& q_{\mathrm{t}}=\frac{C_{0}-C_{\mathrm{t}}}{m} \cdot V \\
& R=\frac{C_{0}-C_{\mathrm{t}}}{C_{0}} \cdot 100
\end{aligned}
$$

where $C_{0}$ and $C_{\mathrm{t}}$ are the initial and $t$ time's concentrations of OTC in the solution $(\mathrm{mg} / \mathrm{L})$, $V$ is the volume of solution (L), and $m$ is the mass of the adsorbent (g).

\subsection{Adsorption kinetics models}

The adsorption process order and the rate constant were estimated by applying the pseudofirst order kinetic [19], pseudo-second order kinetic [20] and intraparticle diffusion [21] models (Table 1), and the model with higher correlation coefficient $\left(R^{2}\right)$ was chosen.

Table 1. The adsorption kinetics models.

\begin{tabular}{|c|c|c|c|}
\hline Model & Linear equation & $\begin{array}{c}\text { Model } \\
\text { parameters }\end{array}$ & Comments \\
\hline $\begin{array}{c}\text { Pseudo-first } \\
\text { order kinetic } \\
\text { model }\end{array}$ & $\log \left(q_{\mathrm{e}}-q_{\mathrm{t}}\right)=\log q_{\mathrm{e}}-\frac{k_{1}}{2.303} \cdot t \quad(3)$ & $\begin{array}{c}k_{1} \text { and } q_{\mathrm{e}} \text { values } \\
\text { were calculated } \\
k_{1}=\text { pseudo first- } \\
\text { order rate } \\
\text { constant }\left(\mathrm{min}^{-1}\right)\end{array}$ & $\begin{array}{c}\text { from the plot of } \\
\log \left(q_{\mathrm{e}}-q_{\mathrm{t}}\right) \text { versus } t ; \\
q_{\mathrm{e}}=\text { adsorption } \\
\text { capacity at } \\
\text { equilibrium }(\mathrm{mg} / \mathrm{g})\end{array}$ \\
\hline $\begin{array}{c}\text { Pseudo- } \\
\text { second order } \\
\text { kinetic } \\
\text { model }\end{array}$ & $\frac{t}{q_{\mathrm{t}}}=\frac{1}{k_{2} \cdot q_{\mathrm{e}}^{2}}+\frac{1}{q_{\mathrm{e}}} \cdot t \quad(4)$ & $\begin{array}{c}k_{2}=\text { pseudo- } \\
\text { second order rate } \\
\text { constant } \\
(\mathrm{g} / \mathrm{mg} \cdot \mathrm{min})\end{array}$ & $\begin{array}{c}k_{2} \text { and } q_{\mathrm{e}} \text { values } \\
\text { were calculated } \\
\text { from the plot of } t / q_{\mathrm{t}} \\
\text { versus } t\end{array}$ \\
\hline $\begin{array}{c}\text { Intraparticle } \\
\text { diffusion } \\
\text { model }\end{array}$ & $q_{\mathrm{t}}=k_{\mathrm{id}} \cdot t^{1 / 2}+c \quad(5)$ & $\begin{array}{c}k_{\mathrm{id}}=\text { intraparticle } \\
\text { diffusion rate } \\
\text { constant } \\
\left(\mathrm{mg} / \mathrm{g} \cdot \mathrm{min} \mathrm{n}^{0.5}\right) ; c= \\
\text { intercept }(\mathrm{mg} / \mathrm{g})\end{array}$ & $\begin{array}{c}k_{\text {id }} \text { and } c \text { values } \\
\text { were calculated } \\
\text { from the plot of } q_{\mathrm{t}} \\
\text { versus } t^{1 / 2}\end{array}$ \\
\hline
\end{tabular}




\section{Results and discussion}

\subsection{Characterization of nanohydroxyapatite adsorbents}

The HA nanopowders were prepared and characterized by XRD, SEM-EDX and BET methods, as reported in previous papers [16, 17]. The uncalcined and calcined HA samples have hexagonal crystal structure, crystal sizes smaller than $100 \mathrm{~nm}$, and a specific surface area of $316 \mathrm{~m}^{2} / \mathrm{g}$ and $139 \mathrm{~m}^{2} / \mathrm{g}$, respectively. The morphology of $H A-u c$ and $H A-c$ samples is shown in SEM micrographs (Fig. 1). The HA-uc sample contains needle-like shape crystallites. Instead, in $H A-c$ sample the particles are agglomerated in spherical-like shape aggregates with an average diameter smaller than $200 \mathrm{~nm}$. Also, the micrographs show irregular and porous surfaces with intergranular porosity.
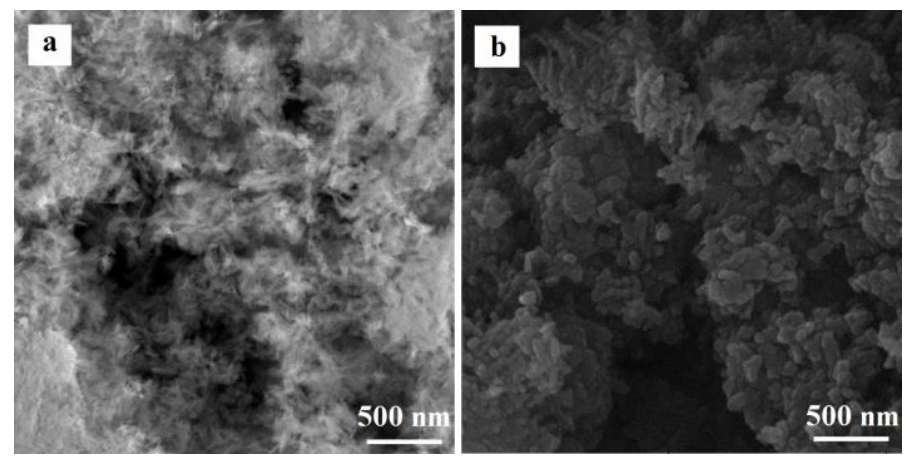

Fig. 1. SEM images of $H A-u c$ (a) and $H A-c$ (b) hydroxyapatite nanopowders.

\subsection{Adsorption of oxytetracycline from solutions}

\subsubsection{Effect of initial $\mathrm{pH}$}

Figure 2a shows the effect of $\mathrm{pH}$ (from 2 to 10 ) on OTC adsorption onto HA samples (at initial OTC concentration $50 \mathrm{mg} / \mathrm{L}$, adsorbent dose $2 \mathrm{~g} / \mathrm{L}$, contact time $1 \mathrm{~h}$, temperature $20 \pm 1{ }^{\circ} \mathrm{C}$ ). The optimum adsorption was found to be at $\mathrm{pH}=8$, with OTC removal rate of about $97.58 \%$ and $89.95 \%$ for $H A-u c$ and $H A-c$ samples, respectively. Lower adsorption of calcined sample can be explained by the calcination process which resulted in a significant decrease of the specific surface area due to particles coalescence and densification. So, $H A$-uc sample is able to hold higher amounts of dyes than $H A-c$ sample.

The removal efficiency of OTC on both HA samples showed a increase when $\mathrm{pH}$ increased from 2 to 8 , and then decreased significantly when $\mathrm{pH}$ was above 8 . This trend can be understood considering the interactions between OTC species and HA surface.

The existence of acid/base-active phenolic hydroxyl and amine groups in OTC (an amphoteric antibiotic) determines that OTC may exist in different ionic species at different solution pHs. The OTC molecule has three acid dissociation constants depending on the $\mathrm{pH}$ $\left(\mathrm{pK}_{\mathrm{a}}=3.57,7.49\right.$ and 9.44) and existed as cationic form in strong acid solutions at $\mathrm{pH}<3.57$, zwitterion at $3.57<\mathrm{pH}<7.49$ and anionic form at $\mathrm{pH}>7.49$ [22].

Likewise, HA acts as an amphoteric material depending on the solution $\mathrm{pH}$ [23]. The $\mathrm{pH}$ at the point of zero charge $\left(\mathrm{pH}_{\mathrm{pzc}}\right)$ of $H A-u c$ and $H A-c$ samples was found to be 6.5 and 6.65, respectively. Hence, for $\mathrm{pH}<\mathrm{pH}_{\mathrm{pzc}}$ the surface of $H A-u c$ and $H A-c$ samples gets positively charged (due to $\equiv \mathrm{CaOH}_{2}{ }^{+}$sites) and for $\mathrm{pH}>\mathrm{pH}_{\mathrm{pzc}}$ is negatively (due to 
$\equiv \mathrm{OPO}_{3} \mathrm{H}^{-}$sites), indicating that the HA surfaces exhibited zwitterionic properties, in good agreement with literature data [24].

The observed $\mathrm{pH}$ effect on the adsorption of OTC onto $H A-u c$ and $H A-c$ samples is related to the molecular structure of OTC and the functional groups present on the surface of HA. The sorption mechanism of OTC on HA surface at $\mathrm{pH}=8$ can be established via surface complexation. Physical mechanisms such as van der Waals forces attraction and hydrogen bonding between OTC molecules and - OH groups on the surface of HA samples may also contribute to surface complexation mechanism in OTC adsorption.
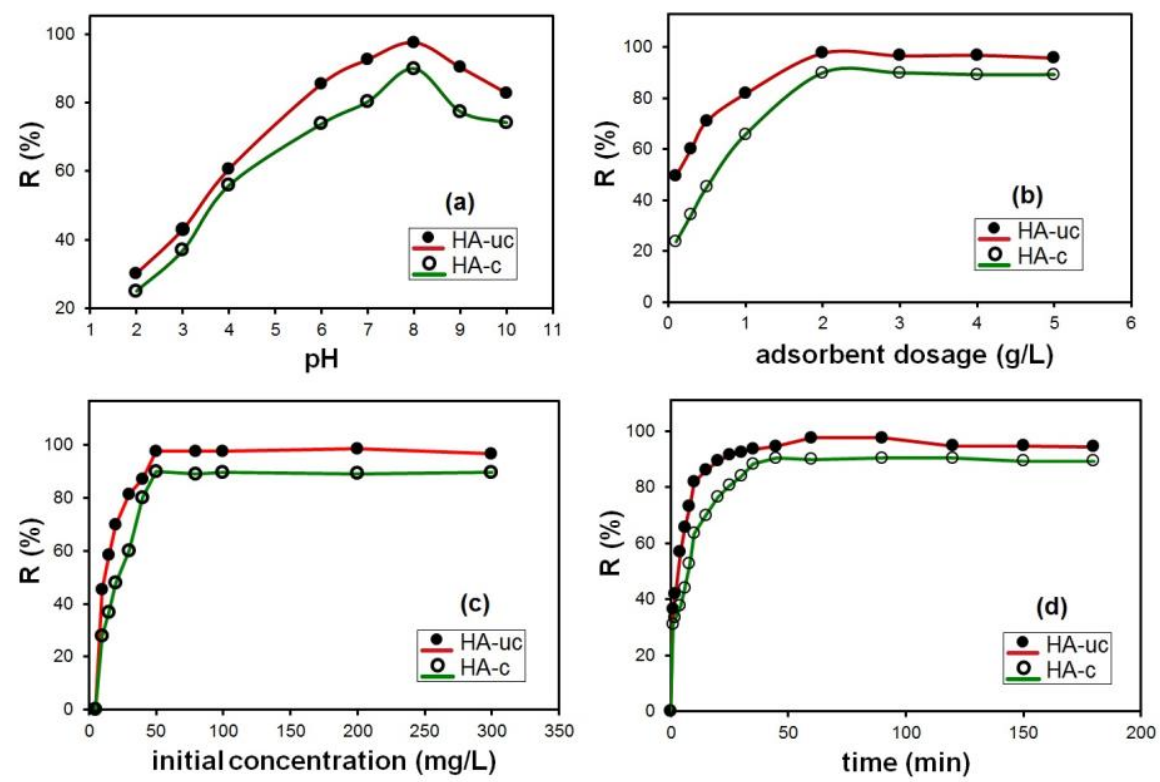

Fig. 2. Effects of initial solution $\mathrm{pH}$ (a), HA adsorbent dosage (b) OTC initial concentration (c) and contact time (d) on OTC adsorption on $H A-u c$ and $H A-c$ samples.

\subsubsection{Effect of adsorbent dosage}

The effect of adsorbent dosage on the OTC removal by HA samples was evaluated in the range of $0.1-5 \mathrm{~g} / \mathrm{L}$ adsorbent, keeping all other parameters constant $(\mathrm{pH}=8$, initial OTC concentration $50 \mathrm{mg} / \mathrm{L}$, contact time $1 \mathrm{~h}$, temperature $20 \pm 1^{\circ} \mathrm{C}$ ). As seen in Fig. $2 \mathrm{~b}$, for both HA samples, the OTC removal rate increased with increasing adsorbent dosage and the maximum was attained at $2 \mathrm{~g} / \mathrm{L}$ adsorbent dose. The increase of OTC removal was due to the increase in surface area and active surface sites available of HA samples. Therefore, in the following investigations the adsorbent dosage of $2 \mathrm{~g} / \mathrm{L}$ was used.

\subsubsection{Effect of initial OTC concentration}

The effect of initial solution concentration was studied by varying the initial OTC concentration from $10-300 \mathrm{mg} / \mathrm{L}$ in the test solution, keeping all other parameters constant ( $\mathrm{pH}=8$, adsorbent dose $2 \mathrm{~g} / \mathrm{L}$, contact time $1 \mathrm{~h}$, temperature $20 \pm 1^{\circ} \mathrm{C}$ ). The amount of OTC adsorbed increased with increase in initial drug concentration tending to saturation at higher drug concentrations (Fig. 2c). At lower concentrations, because the adsorption sites of adsorbent are more, an increase in OTC removal was achieved. At higher concentrations, lower adsorption yield is due to the saturation of adsorption sites. On the other hand, the 
removal degree remained constant for OTC concentration exceeding $50 \mathrm{mg} / \mathrm{L}$. This value was used in the following investigations.

\subsubsection{Effect of contact time}

Adsorption of OTC onto HA samples at different contact time was studied, keeping all other parameters constant $(\mathrm{pH}=8$, initial concentration of OTC $50 \mathrm{mg} / \mathrm{L}$, adsorbent dose $2 \mathrm{~g} / \mathrm{L}$, temperature $20 \pm 1^{\circ} \mathrm{C}$ ). The effects of contact time on the removal of OTC by HA samples are shown in Fig. 2d. Results showed that the adsorption was rapid at the first 15 min and gradually increased with increasing contact time until equilibrium was attained, which was considered at 1 hour. At beginning of adsorption, there existed enough sorption sites on the HA surface which was beneficial to adsorption of OTC. With increasing contact time, sorption sites on the surface of HA samples were close to saturation which made adsorption of OTC transfer from the surface into the void of HA samples.

\subsubsection{Adsorption kinetics models}

In order to analyse the adsorption kinetics for the adsorption of OTC onto $H A-u c$ and $H A-c$ samples, the pseudo-first order, pseudo-second order and intraparticle diffusion models were applied. Figure 3 shows the fitted plots of adsorption kinetic models for OTC by HA samples. The validity of each model is checked by the corresponding correlation coefficients $\left(R^{2}\right)$ as well as the experimental and calculated data summarized in Table 2.
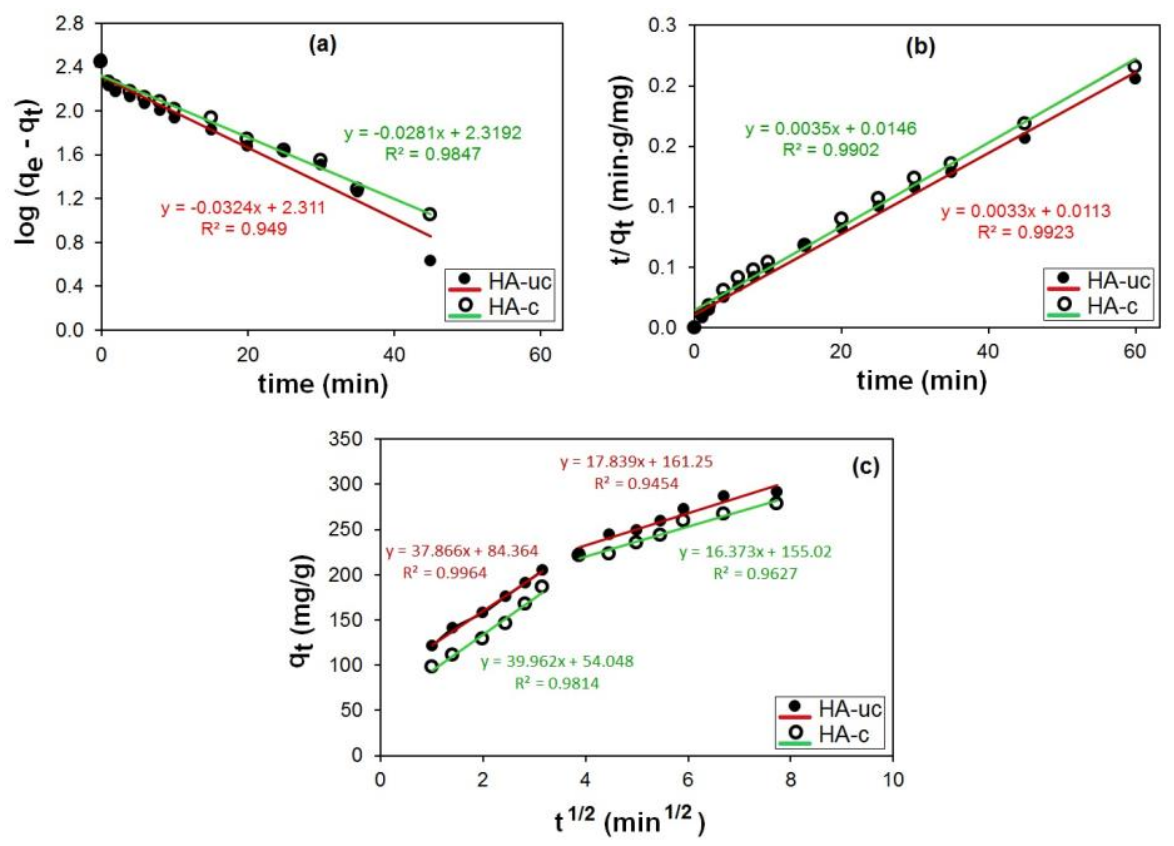

Fig. 3. The pseudo-first order (a), pseudo-second order (b) and intraparticle diffusion (c) kinetic models for OTC adsorption on $H A-u c$ and $H A-c$ samples.

The $R^{2}$ values obtained by the pseudo-second order kinetic model (Fig. 3b) were very high, and the calculated adsorption capacity values $\left(q_{\text {e,calc }}\right)$ in Table 2 were in good agreement with the experimental results $\left(q_{\mathrm{e} \text {,exp }}\right)$, suggesting the applicability of the pseudosecond order kinetic model to describe the adsorption kinetics data of OTC onto HA 
samples. In this case, the adsorption rate limiting step may be chemisorption and the adsorption of OTC occurs probably via surface complexation reactions at specific adsorption sites on HA surface.

To better understand the mechanism of adsorption, the intraparticle diffusion model was applied. The plot of this model (Fig. 3c) could be evaluated in two linear parts. In the first part (phase I) is occurred OTC rapid uptake and the second part (phase II) is associated with the intraparticle diffusion consisting after the accomplishment of external surface coverage by the previous process. The first period is the external surface adsorption or instantaneous diffusion stage, during which a large amount of OTC are rapidly adsorbed by the exterior surface of the adsorbent. When the adsorption of exterior surface reaches saturation, the diffusion resistance increases, leading to the decreased diffusion rate, it is the second period in the adsorption process.

Consistent with the results shown in Fig. 2 d, the OTC adsorption by $H A-u c$ and $H A-c$ samples was achieved at two stages: the rapid surface adsorption (external surface adsorption) in the first stage (first $15 \mathrm{~min}$ ) and the slow intraparticle diffusion (internal surface adsorption) in the second stage (15-60 min). After $60 \mathrm{~min}$, the adsorption reached equilibrium.

Table 2. Kinetic parameters for OTC adsorption on $H A-u c$ and $H A-c$ samples (initial $\mathrm{pH}=8$, adsorbent dose $2 \mathrm{~g} / \mathrm{L}$, initial OTC concentration $50 \mathrm{mg} / \mathrm{L}$, temperature $20 \pm 1^{\circ} \mathrm{C}$ ).

\begin{tabular}{|c|c|c|c|c|}
\hline \multirow{3}{*}{ Kinetic model } & & \multirow{2}{*}{ Parameter } & \multicolumn{2}{|c|}{ Sample } \\
\hline & & & НА-ис & $H A-c$ \\
\hline & & $q_{\mathrm{e}, \exp }(\mathrm{mg} / \mathrm{g})$ & 291.32 & 278.27 \\
\hline \multirow{3}{*}{$\begin{array}{l}\text { Pseudo-first order kinetic } \\
\text { model }\end{array}$} & & $q_{\mathrm{e}, \text { calc }}(\mathrm{mg} / \mathrm{g})$ & 204.64 & 208.55 \\
\hline & & $k_{1}\left(\min ^{-1}\right)$ & 0.0746 & 0.0647 \\
\hline & & $R^{2}$ & 0.9490 & 0.9847 \\
\hline \multirow{3}{*}{$\begin{array}{l}\text { Pseudo-second order } \\
\text { kinetic model }\end{array}$} & & $q_{\mathrm{e}, \mathrm{calc}}(\mathrm{mg} / \mathrm{g})$ & 303.03 & 285.71 \\
\hline & & $k_{2}(\mathrm{~g} / \mathrm{mg} \cdot \mathrm{min})$ & 0.000963 & 0.000839 \\
\hline & & $R^{2}$ & 0.9923 & 0.9902 \\
\hline \multirow{6}{*}{$\begin{array}{l}\text { Intraparticle diffusion } \\
\text { model }\end{array}$} & \multirow{3}{*}{ I } & $k_{\mathrm{id}(\mathrm{I})}\left(\mathrm{mg} / \mathrm{g} \cdot \mathrm{min}^{1 / 2}\right)$ & 37.866 & 39.962 \\
\hline & & $c_{(\mathrm{I})}$ & 84.364 & 54.048 \\
\hline & & $R^{2}(\mathrm{I})$ & 0.9964 & 0.9814 \\
\hline & \multirow{3}{*}{ II } & $k_{\mathrm{id}(\mathrm{II})}\left(\mathrm{mg} / \mathrm{g} \cdot \mathrm{min}^{1 / 2}\right)$ & 17.839 & 16.373 \\
\hline & & $c_{(\mathrm{II})}$ & 161.25 & 155.02 \\
\hline & & $R_{(\mathrm{II})}^{2}$ & 0.9454 & 0.9627 \\
\hline
\end{tabular}

Finally, because of the relatively low-cost of the starting materials and the route used, the resultant hydroxyapatite nanopowders have the potential to be cost-effective adsorbents for the removal of OTC from aqueous solutions.

\section{Conclusions}

In the present study the adsorption of the oxytetracycline (OTC) from aqueous solution on hydroxyapatite (HA) nanopowders was investigated. The batch adsorption experiments were performed and the effects of the initial solution $\mathrm{pH}$, contact time, initial OTC concentration and adsorbent dosage on the OTC adsorption by HA nanopowders were determined. Adsorption process is dependent on $\mathrm{pH}$, and the optimum $\mathrm{pH}$ value was 8 . The adsorption capacity of OTC on uncalcined and calcined samples $(H A-u c$ and $H A-c)$ is up to $291.32 \mathrm{mg} / \mathrm{g}$ and $278.27 \mathrm{mg} / \mathrm{g}$ at experimental condition, respectively. Removal rates of about $97.58 \%$ and $89.95 \%$ for the $H A-u c$ and $H A-c$ samples, respectively, were obtained. The kinetic study made evident a fast adsorption process reaching the equilibrium at a contact time of $60 \mathrm{~min}$ and $\mathrm{pH}=8$, for both samples. It was found that the pseudo-second 
order equation describes in the best way the adsorption kinetics of OTC on calcined and uncalcined HA nanopowders. The adsorption of OTC onto HA samples follows the intraparticle (pore) diffusion model. This means that the adsorption process is not only a surface phenomenon, but also a rate-limiting process in the micro- and nano- porous structure of HA. The obtained results suggest that the OTC adsorption process on HA samples occurs into two main stages. The first stage involves bulk diffusion of OTC to the surface of the adsorbent, while the second one involves intraparticle or pore diffusion processes. The adsorption of OTC proceeds probably via surface complexation reactions at specific adsorption sites on HA surface. The results of present study are indicative of hydroxyapatite as a new alternative low-cost adsorbent for removing the oxytetracycline from wastewaters.

\section{References}

1. J.P. Bound, N. Voulvoulis, Chemosphere 56, 1143-1155 (2004)

2. P. Gao, M. Munir, I. Xagoraraki, Sci. Total Environ. 421-422, 173-183 (2012)

3. M. Rabolle, N.H. Spliid, Chemosphere 40, 715-722 (2000)

4. D. Fatta-Kassinos, S. Meric, A. Nikolaou, Anal. Bioanal. Chem. 399, 251-275 (2011)

5. WHO, Pharmaceuticals in drinking water (WHO Press, Geneva, 2012)

6. A.A. MacKay, B. Canterbury, J. Environ. Qual. 34, 1964-1971 (2005)

7. M. Rabolle, N.H. Spliid, Chemosphere 40, 715-722 (2000)

8. P. Kulshrestha, R.F. Giese, D.S. Aga, Environ. Sci. Technol. 38, 4097-4105 (2004)

9. E.H. Oelkers, E. Valsami-Jones, Elements 4, 83-87 (2008)

10. D.A.C. Manning, Elements 4, 105-108 (2008)

11. S.V. Dorozhkin, J. Funct. Biomater. 6, 708-832 (2015)

12. G. Ciobanu, G. Carja, O. Ciobanu, Surf. Coat. Tech. 202, 2467-2470 (2008)

13. G. Ciobanu, S. Ilisei, C. Luca, G. Carja, O. Ciobanu, Prog. Org. Coat. 74, 648-653 (2012)

14. Y. Nishiyama, T. Hanafusa, J. Yamashita, Y. Yamamoto, T. Ono, J. Radioanal. Nucl. Ch. 307, 1279-1285 (2016)

15. S. Wang, H. Liu, W. Liu, Q. Zuo, J. Biomater. Tiss. Eng. 6, 433-439 (2016)

16. G. Ciobanu, A.M. Bargan, C. Luca, Ceram. Int. 41, 12192-12201 (2015)

17. G. Ciobanu, A.M. Bargan, C. Luca, JOM 67, 2534-2542 (2015)

18. M.N. Khan, A. Sarwar, Surf. Rev. Lett. 14, 461-469 (2007)

19. S. Lagergren, K. Sven. Vetenskapsakad. Handl. 24, 1-39 (1898)

20. Y.S. Ho, G. McKay, Chem. Eng. J. 70, 115-124 (1998)

21. W.J. Weber jr., J.C. Morris, J. Sanit. Eng. Div. 89, 31-60 (1963)

22. S.A. Sassman, L.S. Lee, Environ. Sci. Technol. 39, 7452-7459 (2005)

23. K. Kadlec, K. Adamska, A. Voelkel, Talanta 147, 44-49 (2016)

24. Å. Bengtsson, S. Sjöberg, Pure Appl. Chem. 81, 1569-1584 (2009) 